\title{
Energetic parameters in pregnant and lactating rat (Lasiopodomys brandtii) fed high- or low-fibre diets
}

Adewumi ${ }^{1}$, O. O. Zhang ${ }^{2}$, X. Y. and De-Hua Wang ${ }^{2}$, De-Hua

${ }^{1}$ Department of Animal production and Health, Federal University of Agriculture, Abeokuta, Ogun State, Nigeria

${ }^{2}$ State Key Laboratory of Integrated Management of Pest Insects and Rodents, Institute of Zoology, Chinese Academy of Sciences, Beijing 100101, China

\begin{abstract}
The effect of diet quality (high-fibre (HF) or low-fibre (LF)) on energetic parameters in pregnant and lactating rats (Lasiopodomys brandtii) was examined. There was no significant difference $(p>0.05)$ in body mass of voles prior to dietary acclimation and during pregnancy. Energetic parameters (dry matter, gross energy, digestible energy intake and digestibility) as well as body mass of pups was not significantly $(p>0.05)$ affected by diet quality. Low fibre diet caused a decreased $(p<0.05)$ in feed and gross energy intake and increased $(p<0.001)$ digestible energy intake at mid lactation while digestibility was significantly increased at early lactation. Liver and kidney were significantly $(p<0.05)$ lighter in voles on low fibre diet. No significant difference was observed between diets for metabolic rate. These results revealed that rats can compensate for poor quality (HF) diet physiologically by increasing food intake and decreasing digestible energy intake and digestibility to keep reproductive performance unaffected. The most energetically demanding period of breeding cycle of rat was mid lactation.
\end{abstract}

Key words: Energetic parameters, High- and low-fiber diet, Lactating, Pregnant, Rat

\section{Introduction}

The efficiency of energy intake and energy allocation is critical to the survival and ecological success of mammals living in seasonal environments (Veloso and Bozinovic, 1993). Many wild small mammals show seasonal variations in energy budgets (Bartness et al., 1989; Voltura, 1997; Li and Wang, 2005a) and must consume low-quality or high-fibre food out of necessity rather than by choice during nutritional bottlenecks (Bozinovic, 1995). When fed high-fibre diet, small mammals could increase energy intake to compensate the low digestibility caused by high-fibre content in diet (Karasov and Diamond, 1988; Bozinovic et al., 1997; Owl and Batzli, 1998; Juana et al., 2006).

Brandt's vole, (Lasiopodomys brandtii), also known as the steppe vole, is a species of rodent in the family Cricetidae. They feed mainly on grass (Li and Wang, 2007). Steppe voles are non-hibernating herbivores that inhabit mainly the grasslands of Inner Mongolia of China, Mongolia, and the Baikal region of Russia. These rats are found in Nei Mongol, Jilin, and Hebei provinces in north-east China, in Mongolia and southern Transbaikalia in Russia. Their habitat is dry and pastures and they are sometimes also found in lakeside meadows and river valleys. However, little or nothing is known about the energy intake and allocation in pregnant and lactating steppe voles fed different fibre levels. It is hypothesized that energy intake in pregnant and lactating rat can be increased by low fibre diet and that low 
fibre diet will improve pregnancy and lactation performance of rat. The objective of this work was to examine the effect of fibre levels on reproductive performance, energy intake and oxygen consumption of rat.

\section{Materials and Methods Animals}

Rats (90-120 days old) were the offspring of the voles trapped in Inner Mongolian Grasslands in May 1999 and raised in the Institute of Zoology, Chinese Academy of Sciences. This rat has a gestation length of 20-22 days and lactation length of 2122days. Pups start eating solid food from day 15 of lactation. Virgin voles were housed individually in plastic cages $(30 \mathrm{~cm}$ $\times 15 \mathrm{~cm} \times 20 \mathrm{~cm}$ ) with sawdust and a little cotton as bedding. The voles were kept at 23 $\pm 1^{\circ} \mathrm{C}$, under a photoperiod of $16: 8$-h lightdark cycles (lights on at $0400 \mathrm{~h}$ ).

\section{Experimental animals}

Twenty four rats were used for data collection (twelve rats per treatment). The animals were given free access to either high-fibre diet or low-fibre diet. Nutrient composition of the two diets is presented in Table 1. Two weeks after diet acclimitisation, the females were paired with males (1 male per female) for two days to allow for mating after which the males were removed. The females were thereafter monitored until parturition and during lactation. The body mass of the pups were also monitored. During the test, female voles were housed individually in stainless steel mash metabolic cage $(30 \mathrm{~cm} \times 15 \mathrm{~cm} \times$ $20 \mathrm{~cm}$ ), in which food and water were provided ad libitum. Residual food and faeces were collected after a 3-day test, oven dried at $60^{\circ} \mathrm{C}$ to constant weight and separated manually. The caloric value of food and faeces were determined using Parr 1281oxygen bomb calorimeter (Parr Instruments). The cages were washed while the sawdust and beddings were changed every 3 days.

\section{Energy Intake}

Energy intake was measured at day 6 intervals from the start of the experiment to the end of the experiment as described previously (Liu and Wang, 2007, Song and Wang, 2006). Gross energy intake (GEI) contents of food and faeces were measured by a Parr 1281oxygen bomb calorimeter (Parr Instruments). Gross energy intake (GEI), digestible energy intake (DEI), metabolizable energy intake (MEI), and digestibility (\%) were calculated according to the following equations (Liu et al. 2003):

Dry matter intake (DMI, $\left.\mathrm{gd}^{-1}\right)$

$=$ food intake $\left(\mathrm{gd}^{-1}\right)$

$\mathrm{x}$ dry matter content of food $(\%)$;

Table 1. Nutrient composition of high- and low-fibre diet based on dry mass

\begin{tabular}{lll}
\hline Parameter (\%) & High-fibre diet (HFD) & Low-fibre diet (LFD) \\
\hline Crude fibre & 12.36 & 3.54 \\
Crude fat & 3.94 & 5.44 \\
Crude protein & 16.64 & 21.04 \\
Moisture & 9.58 & 8.86 \\
Ash & 8.68 & 6.33 \\
$\mathrm{Ca}$ & 1.06 & 1.06 \\
$\mathrm{P}$ & 0.72 & 0.87 \\
Caloric value $(\mathrm{kJ} / \mathrm{g})$ & 19.70 & 17.58 \\
\hline
\end{tabular}


GEI $\left(k j * d^{-1}\right)=$ dry matter intake (DMI) $\left(\mathrm{g}^{*} \mathrm{~d}^{-1}\right)$ $x$ gross energy content of food $\left(\mathrm{kj}^{*} \mathrm{~g}^{-1}\right)$

DEI $\left(\mathrm{kj}^{*} \mathrm{~d}^{-1}\right)=$ GEI - [mass of feces $\left(\mathrm{g}^{*} \mathrm{~d}^{-1}\right)$ $\mathrm{x}$ gross energy content of feces $\left(\mathrm{kj}^{*} \mathrm{~g}^{-1}\right)$ ]

Digestibility (\%)

$=\mathrm{DEI} / \mathrm{GEI} X 100 \%$

\section{Metabolic trials}

Resting metabolic rate (RMR) was measured on day 18 of lactation by using an established closed-circuit respirometer at $30 \pm 0.5^{\circ} \mathrm{C}$ (within their thermal neutral zone) as described previously (Wang et al. 2000; Li and Wang 2005b). Briefly, the metabolic chamber volume was $3.6 \mathrm{~L}$ and the temperature inside the chamber was maintained by a water bath. $\mathrm{KOH}$ and silica gel were used to absorb carbon dioxide and water, respectively, in the metabolic chamber. The voles were weighed before and after each test. After 60 minutes stabilization in the chamber, oxygen consumption was recorded for another 60 minutes at 5 minutes intervals. Two stable consecutive lowest readings will be taken to calculate RMR and corrected to standard temperature and pressure (STP). All metabolic measurements were taken between 0900 and 1700 hours to minimize any effects of circadian rhythms. Maternal Body Composition

After the 18 days of experiments, the dams were asphyxiated by $\mathrm{CO}_{2}$ overdose between 09:00 $\mathrm{h}$ and 11:00 $\mathrm{h}$. The interscapular BAT (IBAT) was immediately removed and dissected, weighed, and stored at $80^{\circ} \mathrm{C}$ until assayed. After interscapular BAT was removed, the visceral organs, including heart, lung, liver, kidneys, spleen, uterus and gastrointestinal tract (stomach, small intestine, cecum, proximal colon and distal colon) were extracted and weighed $( \pm 1$ $\mathrm{mg}$ ). The gastrointestinal tract was rinsed with saline to remove its contents and weighed. The body mass without visceral organs was defined as wet carcass mass.

Statistical analysis

All data were expressed as mean $\pm \mathrm{SE}$. Differences in parameters measured were determined by independent samples t-tests. Body mass variation was measured with repeated measurements followed by Tukey's HSD post-hoc to determine the daily variation. Data were analysed using the SPSS 2007 software package. Statistical significance was assumed at $\mathrm{P}<0.05$.

\section{Results}

Body mass of dams and pups

There were no differences in body mass prior to dietary acclimitisation, body mass of control (high fibre) and low fibre vole averaged (day 0, HF, $35.37 \pm 1.13$; LF, $35.93 \pm 0.76 \mathrm{~g} ; F_{1,22}=3.841, \mathrm{P}>0.05$ Fig. 1 ). Generally, body mass of Vole dams fed high fibre diet were slightly higher than those on low fibre diet during pregnancy and lactation. Also, there was no significant effect of diet on body mass (BM, g) of rat throughout pregnancy and lactation, although body mass was slightly low in HF voles on day $21(\mathrm{HF}, 42.61 \pm 2.36$; LF, $\left.42.65 \pm 1.46 \mathrm{~g} ; F_{1,22}=2.970, \mathrm{P}>0.05\right)$ of pregnancy and day 15 (HF, 51.48 2.37 ; LF, $\left.52.23 \pm 1.77 ; F_{1,22}=1.131, \mathrm{P}>0.05\right)$ of lactation (Fig. 1). The body mass of high and low fibre lactating voles decreased as lactation advanced. Pups body mass of high and low fibre vole averaged (day 0, HF, $21.98 \pm 1.67$; LF, $18.23 \pm 1.25 \mathrm{~g} ; F_{1,22}=$ $1.629, \mathrm{P}>0.05)$. Also, pups body mass was not significantly affected by diet throughout lactation (Fig. 2). The 


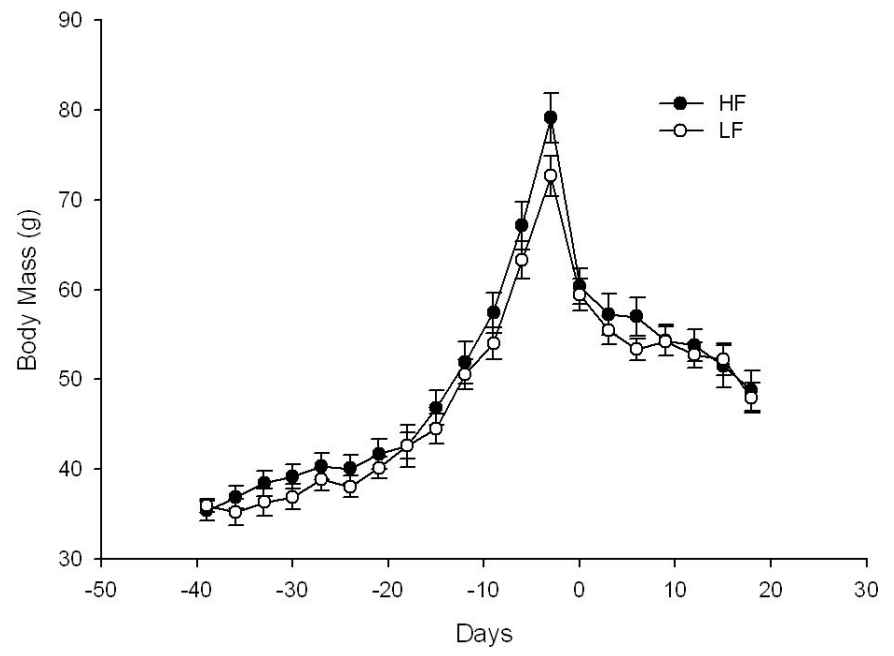

Fig. 1. Changes in body mass responding to high-fibre diet (HF) and low fibre diet (LF) during 14 days of acclimatisation, 21 days pregnancy and 18 days lactation in Brandt's voles. Highfibre voles did not differ significantly during acclimatisation, pregnancy and lactation. Data are mean \pm SE. P $>0.05$

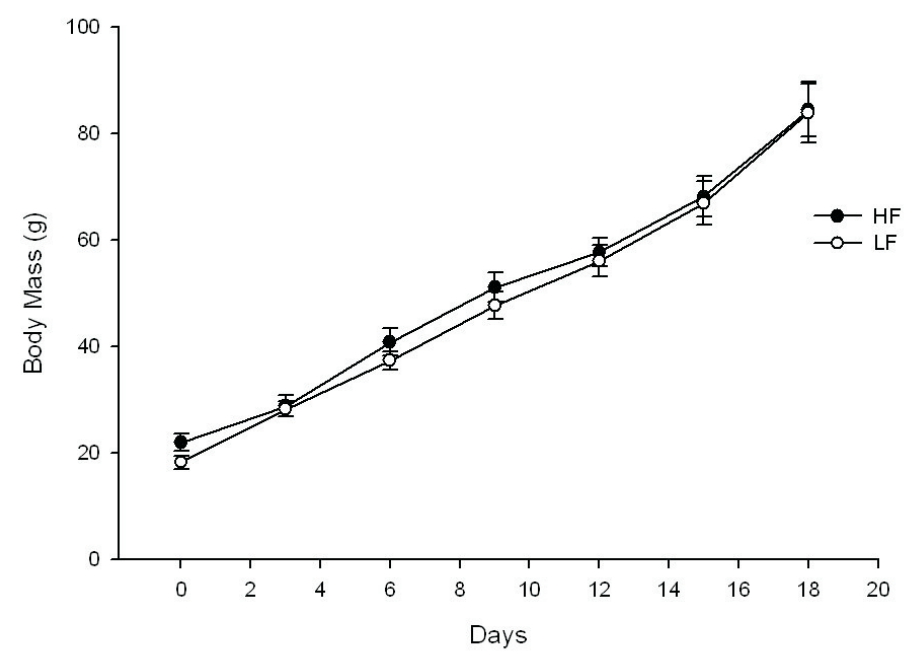

Fig. 2 Body mass of Brandt's voles pups whose mother's were fed high and low fibre diet. Data are mean \pm SE. $P>0.05$ 
difference was not significant $(\mathrm{P}>0.05)$. The interaction between diet and time was not significant $\left(\mathrm{F}_{23,456}\right)=1.521$

Dry matter intake during pregnancy

The DMI of Voles increased, on average, from $7.82 \pm 0.75 \mathrm{~g}$ on day 6 of pregnancy to $10.15 \pm 0.95 \mathrm{~g}$ on day 18 for high fibre diet and from $5.84 \pm 0.51 \mathrm{~g}$ on day 6 of pregnancy to $8.78 \pm 0.35 \mathrm{~g}$ on day 18 of pregnancy for rats on low fibre diet (Fig. 3). This intake was equivalent to a gross energy intake of $132.07 \pm 12.75 \mathrm{~kJ} /$ day on day 6 of pregnancy to $171.64 \pm 16.11 \mathrm{~kJ} /$ day on day 18 for rats on high fibre diet and $103.19 \pm$ $9.10 \mathrm{~kJ} /$ day on day 6 to $(155.09 \pm$ $6.26 \mathrm{~kJ} /$ day) on day 18 for rats on low fibre diet.

Energy intake during lactation

The daily feed intake increased, on average, from $11.38 \pm 1.28 \mathrm{~g}$ on day 6 of lactation to $15.18 \pm 2.23 \mathrm{~g}$ on day 18 in voles on high fibre diet and from $8.35 \pm 1.31 \mathrm{~g}$ on day 6 of lactation to $12.97 \pm 0.75 \mathrm{~g}$ on day 18 in voles on low fibre diet (Fig. 3). This intake was equivalent to a gross energy intake of $192.28 \pm 28.42 \mathrm{~kJ} /$ day on day 0 of lactation to $256.56 \pm 37.80 \mathrm{~kJ} /$ day on day 18 for the high fibre diet and $147.60 \pm 16.20 \mathrm{~kJ} /$ day and on day 0 of lactation and $229.21 \pm$ $13.21 \mathrm{~kJ} /$ day on day 18 in voles on low fibre diet. Dry matter intake and GEI in HF voles were significantly higher than LF voles at mid lactation (DMI $\mathrm{F}_{1,10}=0.011, \mathrm{P}<0.05$, GEI $\left.F_{1,10}=10.55, P<0.05\right)$. Feed and energy intake increased in voles on high fibre diet by $89 \%$ at mid lactation when compared with voles on low fibre diet. However, digestible energy intake and digestibility were significantly lower in HF voles at mid lactation (DEI, $\mathrm{F}_{(1,10)}=77.628 ; \mathrm{P}<0.001$ ) and (DIG, $\mathrm{F}_{(1,10)}=4.38, \mathrm{P}<0.05$ ) respectively. Basal metabolic rate

Diet had no significant $(\mathrm{P}>0.05)$ effect on oxygen consumption of lactating voles. The average values were $191.48 \pm 86.01$ and
$193.79 \pm 80.97 \mathrm{ml} / \mathrm{h} / \mathrm{g}$ for high and low fibre diet respectively (Table 2).

Bodycomposition

There was no significant $(\mathrm{P}>0.05)$ effect of diet on body composition of lactating voles except for liver and kidney that were significantly higher in high fibre voles Table 2.

\section{Discussion}

The present study showed that there were no differences in body mass during acclimitisation, pregnancy and lactation. However, voles on high fibre diet had a slightly higher body mass as compared to voles on low fibre diet. A previous study on growing voles showed lower body mass in high-fibre compared to low-fibre voles (Zhao and Wang, 2007). Voles on high and low fibre diet showed a steady decrease in body mass. This is consistent with the report of Zhang and Wang, (2007). Higher body mass in voles on HF diet may be due to increased body fat mass. Low fibre diet stimulated increase in metabolic rate. Dry matter intake and GEI were higher in voles fed high fibre diet than voles fed low fibre. This implies that rat can physiologically regulate energy parameters and metabolic rate in response to changes in food quality. The increase in dietary fibre intake from voles on high fibre diet can result in decreased in digestibility (Zhao and Wang, 2007), which was confirmed in this study. In other words, food with poor nutritional contents had to be consumed in higher amounts to meet the normal and/or higher physiological requirements (Cork and Foley, 1991; Veloso and Bozinovic, 1993). Animals on lower calorie intake were able to enhance their digestive efficiency to extract more energy from digested food (Hambly and Speakman, 2005). For rat, the higher digestibility in low fibre diet group was likely to compensate for the decrease in 
Energetic parameters in pregnant and lactating rat fed high-or low-fibre diets 
Adewumi, Zhang and De-Hua Wang 
Energetic parameters in pregnant and lactating rat fed high-or low-fibre diets

Table 2: Body composition (g) and oxygen consumption $(\mathrm{ml} / \mathrm{h} / \mathrm{g})$ of lactating Brandt's vole fed low and high fibre diet

\begin{tabular}{lllll}
\hline Body traits & $\begin{array}{l}\text { High-fibre } \\
\mathrm{N}=12\end{array}$ & $\begin{array}{l}\text { Low-fibre } \\
\mathrm{N}=12\end{array}$ & $P$ value & $F(1,22)$ \\
\hline Body mass & $46.88 \pm 1.94$ & $46.31 \pm 1.49$ & $\mathrm{~ns}$ & 0.65 \\
Oxygen (BMR) & $191.48 \pm 86.01$ & $193.79 \pm 80.97$ & $\mathrm{~ns}$ & 0.58 \\
BAT1 & $0.07 \pm 0.01$ & $0.06 \pm 0.01$ & $\mathrm{~ns}$ & 0.06 \\
BAT2 & $0.07 \pm 0.01$ & $0.06 \pm 0.01$ & $\mathrm{~ns}$ & 0.41 \\
Liver & $2.46 \pm 0.18^{\mathrm{a}}$ & $2.35 \pm 0.88^{\mathrm{b}}$ & $(\mathrm{p}<0.05)$ & 5.83 \\
Heart & $0.22 \pm 0.01$ & $0.22 \pm 0.01$ & $\mathrm{~ns}$ & 2.40 \\
Lungs & $0.34 \pm 0.02$ & $0.36 \pm 0.02$ & $\mathrm{~ns}$ & 1.80 \\
Kidney & $0.56 \pm 0.04^{\mathrm{a}}$ & $0.50 \pm 0.01^{\mathrm{b}}$ & $(\mathrm{p}<0.05)$ & 5.78 \\
Spleen & $0.04 \pm 0.01$ & $0.04 \pm 0.01$ & $\mathrm{~ns}$ & 0.09 \\
Stomach & $0.39 \pm 0.02$ & $0.36 \pm 0.02$ & $\mathrm{~ns}$ & 0.17 \\
Small Intestine & $0.75 \pm 0.07$ & $0.86 \pm 0.05$ & $\mathrm{~ns}$ & 2.03 \\
Caecum & $0.61 \pm 0.04$ & $0.68 \pm 0.05$ & $\mathrm{~ns}$ & 0.26 \\
Colon & $0.51 \pm 0.04$ & $0.64 \pm 0.13$ & $\mathrm{~ns}$ & 0.47 \\
Gonad & $0.12 \pm 0.01$ & $0.12 \pm 0.01$ & $\mathrm{~ns}$ & 0.15 \\
Mammary gland & $1.01 \pm 0.15$ & $0.91 \pm 0.12$ & $\mathrm{~ns}$ & 0.49 \\
Carcass & $26.98 \pm 1.01$ & $25.29 \pm 0.86$ & $\mathrm{~ns}$ & 0.10 \\
& & & & \\
\hline
\end{tabular}

gross energy intake (Peacock and Speakman, 2010). Together, these results indicated that high quality food associated with high digestibility might contribute to increased metabolic rate. When fed highfibre diet, small mammals could increase energy intake to compensate for low digestibility caused by high fibre content in diet The increase in DMI and GEI and decreased in DIG in Voles fed high fibre diet as compared with Voles on low fibre diet is in agreement with Zhao and Wang (2007). Energy demands increase with the process of reproduction; therefore, the maintenance of proper body mass is essential to the survival and breeding in small mammals. The higher energy demands during reproduction were mainly met by increased energy intake with a few exceptions such as some bats (Mclean and Speakman, 1999). In the present and previous studies, voles on low fibre diet recorded higher digestibility than those on high fibre diet thus corroborating Zhao and
Wang (2007). These data suggest that the female voles increased energy intake to meet the high energy demand for fetus development and milk production.

Lactation is a state characterized by negative energy balance in the lactating female, due to the profound energy drain resulting from milk production (Li et al., 1998). Generally, rat increased energy intake during lactation, that is, they rely mainly on increased energy intake and reduce digestibility to meet the high energy demands of reproduction (Mattingly and McClure, 1982; Millar, 1987). The increase in energy demand during lactation is usually met by increased food intake in small mammals (Bartness, 1997; Johnstone and Higuchi, 2001; Speakman and Król, 2005), such as cotton rats (Sigmodon hispidus) (Randolph et al., 1977), northern grasshopper mice (Onychomysleucogaster) (Sikes, 1995), laboratory mice (Musmusculus) (Johnson et al., 2001), and rat (Liu et al., 2003). The high digestibility 
associated with low fibre implies that low fibre diet reduces the work of enzymes and the requirement for large surface area for absorption of nutrient. However, different results can be found under natural conditions, for example large-littered species mobilized relatively more energy reserves during lactation and had a lower probability of encountering an energy shortage than the small-littered species (Millar, 1987; Zhang and Wang, 2008).

It has been known that changes in basal metabolic rate (BMR), one of the major component of total energy expenditure are important in the regulation of energy budgets and body mass in many small mammals in response to environmental fluctuations including temperature, photoperiod or food (Peacock and Speakman, 2010). In this study, significant effect of diet on BMR was not observed, although, it has been previously reported that poor quality food could decrease BMR (Zhao and Wang, 2007, Veloso and Bozivonia, 1993).

In the current study, voles on high fibre diet had increased liver and kidney weights suggesting an adaptive mechanism to cope with the high feed intake associated with voles on high fibre. The increase in mass especially the enlargement of liver has been known to contribute to dam's increased energy expenditure for maintenance (Zhang and Wang, 2008). Liver is the site of cytochrome c oxidase (COX) activity which is associated with thermogenesis (Zhang and Wang, 2008).

\section{Conclusion}

There were no significant differences in body mass of dams and pups fed high and low fibre diet. Dry matter and gross energy intake were significantly higher in voles on high fibre diet as compared to voles on low fibre diet at mid lactation only while digestible energy intake and digestibility were significantly lower in high fibre fed voles at mid lactation. Visceral organs such as liver and kidney were significantly higher in voles on high fibre diet. Therefore, voles on high fibre level can compensate the poor quality diet physiologically by increasing food intake and decreasing basal metabolic rate. This result suggests that voles adjusts body mass, energy parameters and basal metabolic rate to meet the high demands of pregnancy and lactation and mid-lactation is the most energetically demanding period of the breeding cycle.

\section{Recommendation}

Diet of high quality and quantity should be fed to voles particularly at mid-lactation.

\section{Acknowledgements:}

Thanks to all members of the Animal Physiological Ecology Group of the Institute of Zoology, Chinese Academy of Sciences for their cooperation during the experiment. This study was supported financially by the Third World Academy of Sciences (TWAS) and the Chinese Academy of Sciences (CAS). In addition, I appreciate the Federal University of Agriculture, Abeokuta, Ogun State, Nigeria for providing the logistics.

\section{References}

Bartness, T.J. Elliott, J.A., Goldman, B.D. 1989. Control of torpor and body weight patterns by a seasonal timer in Siberian hamsters, Am J Physiol 257, R142-R149.

Bozinovic, F. 1992. Scaling of basal and maximum metabolic rate in rodents and the aerobic capacity model for the evolution of endothermy. Physiol.Zool. 65, 921-932.

Bozinovic, F., Novoa, F.F. and Sabat, P. 
1997. Feeding and digesting fibre and tannins by an herbivorous rodent Octodon degus (Rodentia: Caviomorpha). Comp. Biochem. Physiol. A 118, 625-630.

Bozinovic, F. 1995. Nutritional energetics and digestive responses of an herbivorous rodent (Octodon degus) to different levels of dietary fibre. J.Mammal. 76, 627-637.

Cork, S.J. and Foley, W.J. 1991. Digestive and metabolic strategies of arboreal mammalian folivores in relation to chemical defense in temperate and tropical forest. In: Palo, R.T., Robbins, C.T. (Eds.), Plant Defense

Hambly, C. and Speakman, J.R. 2007. Contribution of different mechanisms to compensation for energy restriction in the mouse. Obes. Res. 13: 15481557.

Johnson, M.S., Thomson, S.C. and Speakman, J.R., 2001. Limits to sustained energy intake. III. Effects of concurrent pregnancy and lactation in Mus musculus, J. Exp. Biol. 204, 1947-1956.

Johnstone, L.E., and Higuchi, T., 2001. Food intake and leptin during pregnancy and lactation, Prog. Brain Res. 133, 215-227.

Juana, C.V., Cristina, B. and Alejandra, A.L.M. 2006. Phenotypic plasticity in response to low quality diet in the South American omnivorous rodent Akodon azarae (Rodentia: Sigmodontinae). Comp. Biochem. Physiol. A 145, 397-405.

Karasov, W.H. and Diamond, J.M. 1983. Adaptive regulation of sugar and amino acid transport by vertebrate intestine. Am J Physiol;245:G443-62.

Li, X.S. and Wang, D.H., 2005a. Regulation of body weight and thermogenesis in seasonally acclimatized rats (Microtus brandtii), Horm. Behav. 48, 321-328.

Li, X.S., Wang, D.H., 2005b. Seasonal adjustments in body mass and thermogenesis in Mongolian gerbils (Meriones unguiculatus): the roles of short photoperiod and cold. J. Comp. Physiol., B 175, 593-600.

Li, C., Chen, P. and Smith, M.S. 1998. The acute suckling stimulus induces expression of neuropeptide Y (NPY) in cells in the dorsomedial hypothalamus and increases NPY expression in the arcuate $\mathrm{nucleus}$. Endocrinology 139:1645-1652

Liu, H., Wang, D.H. Wang, Z.W., 2003. Energy requirements during reproduction in female Rats (Microtus brandtii), J. Mammal. 84, 1410-1416.

Liu, Q.S., Wang DH. 2007 Effects of diet quality on phenotypic flexibility of organ size and digestive function in Mongolian gerbils (Meriones unguiculatus). J Comp Physiol [B] 177: 509-518,.

Mattingly, D.K. and McClure, P.A. 1982. Energetics of reproduction in large littered cotton rats (Sigmodon hispidus). Ecology 63:183-195

Millar, J.S. 1987. Energy reserves in breeding small rodents. Symp Zool Soc Lond 57:231-240

Owl, M.Y. and Batzli, G.O. 1998. The integrated processing response of voles to fibre content of natural diets. Funct. Ecol. 12, 4-13.

Randolph, P.A., Randolph, J.C., Mattingly, K.. and Foster, M.M. 1977. Energy costs of reproduction in the cotton rat (Sigmodon hispidus), Ecology 58, 31-45

Sikes RS 1995. Cost of lactation and optimal litter size in northern 
grasshopper mice (Onychomys leucogaster). JMamma1 76:348-357

Song, Z.G. and Wang, D.H. 2006. Basal metabolic rate and organ size in rat (Lasiopodomys brandtii) effectsof photoperiod, temperature and diet quality. Physiol. Behav. 89:704-710.

Speakman J.R. and Król, E. 2005. Limits to sustained energy intake. IX. A review of hypotheses, J. Comp. Physiol. B 175, 375-394.

Wang, D.H., Wang, Y.S. and Wang, Z.W., 2000 . M e t a bolis m and thermoregulation in the Mongolian gerbil (Meriones unguiculatus). Acta Theriologica 45, 183-192.

Veloso, C. and Bozinovic, F. 1993. Dietary and digestive constraints on basal energy metabolism in a small herbivorous rodent, Ecology 74, pp. 2003-2010.

Voltura, M.B. 1997. Seasonal variation in body composition and gut capacity of the prairie vole, Microtus ochrogaster. Can. J. Zool. 75, 1714-1719.

Zhao Z.J. and H. Wang. 2007. Short period enhances thermogenic capacity in rat. Physiological Behaviour 85: 143-149.

Zhang, X.Y. and Wang, D.H., 2007. Effect of diet quality on energy budgets and thermogenesis in rat. Comp Biochem Physiol. Part A 148: 168-177.

Received: $18^{\text {th }}$ November, 2013 Accepted: $21^{\text {st }}$ January, 2015 